\title{
Bioinformatics Analysis of Domain 1 of HCV-Core Protein: Iran
}

\author{
Behzad Dehghani ${ }^{1} \cdot$ Tayebeh Hashempour $^{1} \cdot$ Zahra Hasanshahi $^{1} \cdot$ Javad Moayedi $^{1}$
}

Accepted: 8 March 2019 / Published online: 20 April 2019

(c) Springer Nature B.V. 2019

\begin{abstract}
Hepatitis C virus (HCV) infection is a serious global health problem and a cause of chronic hepatitis, liver cirrhosis, and hepatocellular carcinoma (HCC). Bioinformatics software has been an effective tool to study the HCV genome as well as core domains. Our research was based on employing several bioinformatics software applications to find important mutations in domain 1 of core protein in Iranian HCV infected samples from 2006 to 2017, and an investigation of general properties, B-cell and T-cell epitopes, modification sites, and structure of domain 1. Domain 1 sequences of $188 \mathrm{HCV}$ samples isolated from 2006 to 2017, Iran, were retrieved from NCBI gene bank. Using several tools, all sequences were analyzed for determination of mutations, physicochemical analysis, B-cell epitopes prediction, T-cell and CTL epitopes prediction, post modification, secondary and tertiary structure prediction. Our analysis determined several mutations in some special positions (70, 90, 91, and 110) that are associated with HCC and hepatocarcinogenesis, efficacy of triple therapy and sustained virological response, and interaction between core and CCR6. Several B-cell, T-cell, and CTL epitopes were recognized. Secondary and tertiary structures were mapped fordomain 1 and core proteins. Our study, as a first report, offered inclusive data about frequent mutation in $\mathrm{HCV}$-core gene domain 1 in Iranian sequences that can provide helpful analysis on structure and function of domain 1 of the core gene.
\end{abstract}

Keywords $\mathrm{HCV} \cdot$ Core $\cdot$ Domain $1 \cdot$ Bioinformatics

\section{Introduction}

$\mathrm{HCV}$ infection is a serious global health problem and causes chronic hepatitis, liver cirrhosis, and HCC (Akuta et al. 2007; Ajorloo et al. 2015; Alborzi et al. 2017, 2015; Moayedi et al. 2018; Hashempoor et al. 2018). It is estimated that 160 million people are infected worldwide (Lavanchy 2011). The prevalence rate of $\mathrm{HCV}$ infection is from 0.2 up to $40 \%$ in different countries, and this prevalence in Iran is $0.16 \%$ (Sefidi et al. 2013).

Lack of an effective vaccine and therapeutic choices has leaded to the rapid growth of $\mathrm{HCV}$ infection (Lauer and Walker 2001).

HCV has six large different genotypes (1-6) and 70 distinct subtypes (a, b, c, etc.) globally (Martro et al. 2011). Genotyping analysis showed 30-33\% difference in each genotype, and in subtypes around 20-25\% (Sefidi et al. 2013).

Tayebeh Hashempour

thashem@sums.ac.ir

1 Shiraz HIV/AIDS Research Center, Institute of Health, Shiraz University of Medical Sciences, Shiraz 71937, Iran
According to the current investigations in Iran, the predominant HCV subtype is $1 \mathrm{a}$, followed by $3 \mathrm{a}$ and $1 \mathrm{~b}$ (Sefidi et al. 2013).

$\mathrm{HCV}$ is a positive-strand RNA virus encoding three structural components, the core protein, and two E1 and E2 envelope glycoproteins (Ajorloo et al. 2015).

The core protein has many confirmed roles: core binds RNA and DNA and has an important function in RNA packing. It has been determined that $\mathrm{HCV}$-core is a nucleic acid chaperone similar to retroviral nucleocapsid (NC) proteins in act acting to rearrange HCV 3'UTR, resulting in RNA dimerization in vitro (Caval et al. 2011; Cristofari Gl; Ivanyi-Nagy et al. 2004; Steinmann et al. 2008).

$\mathrm{HCV}$-core is a highly basic protein that forms the viral $\mathrm{NC}$ and has interactions with cellular proteins and signal transduction pathways. As a result of HCV-core and host cell interactions, core may have a function in persistent infection and the pathogenesis of HCV liver disease (Polyak et al. 2006; Hashempour et al. 2015).

Core protein consisted of three predicted domains: aa1-aa117 domain 1 (domain D1), aa117-aa177 domain 2 
(domain D2), and 177-191 domain 3 (domain D3) (Strosberg et al. 2010).

Domain 1 contains frequent positively charged amino acids, and is involved in RNA binding, promotes dimerization of the viral RNA, and has a significant role in NC formation and core envelopment by endosomal membranes (Ivanyi-Nagy et al. 2006).

Several identified mutations in domain 1 are involved in the development of HCC and hepatocarcinogenesis, the efficacy of triple therapy, and interaction between core and CXCL6 (Akuta et al. 2007, 2010, 2011; Fishman et al. 2009; Ogata et al. 2002; Takahashi et al. 2001; Idrees and Ashfaq 2013).

Humoral and cellular immune responses against HCV infections are inefficient and there is no convincing explanation to understand HCV immune pathogenesis (Gremion and Cerny 2005). However, HCV-specific IgM and IgG together were detected in acute infection. There are some outstanding proofs supporting a role for Abs in control of $\mathrm{HCV}$ infection and especially in reinfection (Cashman et al. 2014).

Some researchers have described a rise in anti-HCV humeral immune after immunization with core protein (Aghasadeghi et al. 2006). Other researchers have claimed that in acute $\mathrm{HCV}$ infection the titer of antibodies is very low, and delay in neutralizing antibody production is responsible for ineffective ability to prevent HCV infection (Netski et al. 2005). Other sources have introduced a large diversity of epitopes in $\mathrm{HCV}$ proteins as a possible way to escape the humoral response (Pavio and Lai 2003).

Cellular immune responses have an important role in the clearance of HCV infection. Patients with cellular immune dysfunction like human immunodeficiency virus (HIV) have rapid $\mathrm{HCV}$ progression. Some researchers have claimed that this system promotes liver injury by cytolysis activity of infected cells. In spite of cellular immune responses, HCV often evades recognition and has the ability to persist (Ward et al. 2002).

Several studies have described a number of pathways for HCV to escape from cell responses, including impaired oligo-/mono-specific or no virus-specific $\mathrm{CD} 4^{+}$and $\mathrm{CD} 8^{+}$, mutation of epitopes, weakness of proliferative capacity, and cytotoxicity and ability to secrete TNF- $\alpha$ and IFN- $\gamma$ by $\mathrm{CD}^{+} \mathrm{T}$ cells (Neumann-Haefelin et al. 2005). In addition, regulatory $\mathrm{T}$ cells (Tregs) induced by HCV infection have a significant role in the impaired activity of cellular immune response (Hashempour et al. 2015; Hashempoor et al. 2010).

Bioinformatics tools are efficient means to study viruses and different parts of the HCV genome like core domains (Idrees and Ashfaq 2013; Moattari et al. 2015; Dehghani et al. 2017; Nezafat et al. 2018; Atapour et al. 2018; Sarvari et al. 2014; Behzad Dehghani and Zahra Hasanshahi 2019). Bioinformatics tools are efficient means to study viruses and different parts of the HCV genome like core domains. Many programs have been developed to analyze function, structures, and modification of core protein, providing a large amount of information about core domains and important mutation sites (Akuta et al. 2007, 2010, 2011).

Current data are useful for prediction of HCV disease development and treatment response. In this study, we employed several bioinformatics tools to find important mutations in domain 1 of the core protein, general properties of B-cell and T-cell epitopes, modification sites, and structure of domain 1 in Iranian HCV infected samples from 2006 to 2017.

\section{Materials and Methods}

\section{Sequence Alignment and Phylogenetic Tree}

Domain 1 sequences of 188 Iranian HCV samples and reference sequences of $\mathrm{HCV}$ genotypes that were registered in NCBI gene bank (http://www.ncbi.nlm.nih.gov/) from 2006 to 2017 were downloaded. Homology among sequences was determined using multiple sequence alignment available in CLC- sequence viewer software under the following parameters: gap open cost, 10; gap extension cost, 1.0; and very accurate progressive alignment algorithm. Also, phylogenetic trees were analyzed through CLUSTAL X software, version 1.81 , by neighbor-joining times to confirm the reliability of phylogenetic trees. The accession numbers of all sequences are displayed in Table 1.

\section{Determination of Mutations}

By considering previous studies, several significant mutations that are involved in: 1-hepatocellular carcinoma, 2-viral response to triple therapy, and 3-the interaction between core and CXCL6, were determined. All sequences were compared to find mentioned mutations (Akuta et al. 2007; Fishman et al. 2009; Ogata et al. 2002).

\section{Physico-chemical Analysis}

General properties of domain 1 (genotype 1a) were determined by employing "Expasy'sProtParam" (http://expas y.org/tools/protparam.html) and ProtScale at (http://web. expasy.org/protscale/) (Gasteiger et al. 2005).

\section{B-Cell Epitopes Prediction}

Chou and Fasman, Karplus and Schulz, Kolaskar \& Tongaonkar, Emini, Parker, and BepiPred methods at http:// www.immuneepitope.org (http://tools.immuneepitope.org/ tools/bcell/iedb_input) were run for prediction of B-Cell epitopes positions (Chou and Fasman 2009; Karplus and 


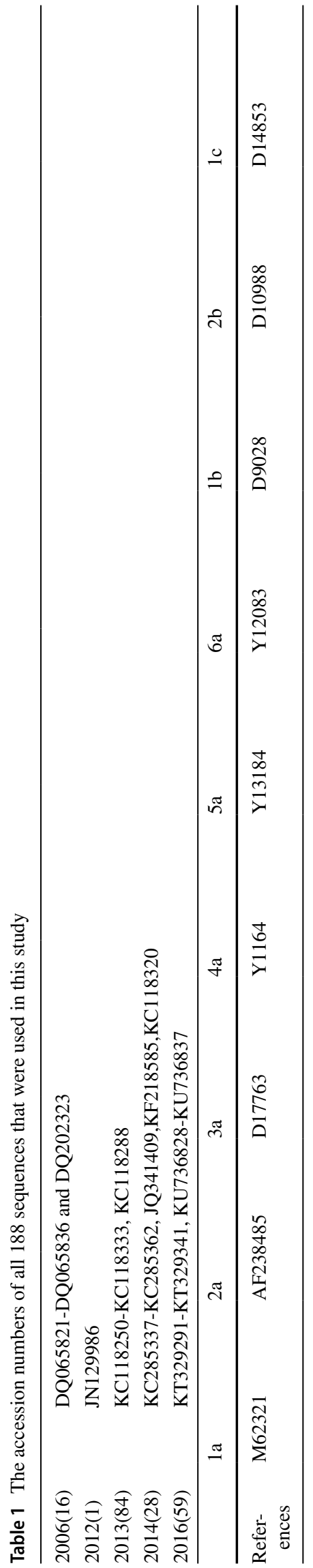

Schulz 1985; Emini et al. 1985; Parker et al. 1986; Larsen et al. 2006).

On hydrophilicity, flexibility/mobility, accessibility, polarity, exposed surface and turns features by BcePred (http://www.imtech.res.in/raghava/bcepred) B-cell epitopes prediction were performed (Saha and Raghava 2004).

ABCpred software (http://www.imtech.res.in/raghava/ abcpred/) predicted 16 meric B-cell epitopes (Saha and Raghava 2006a, b).

\section{Prediction of T-Cell, CTL Epitopes and Allergic Properties}

ProPred-I (http://www.imtech.res.in/raghava/propred1/) (Singh and Raghava 2003) was employed for MHC ClassI binding peptide prediction and proposed (http://www. imtech.res.in/raghava/propred/) was used for MHC Class-II binding peptide prediction. Programs were worked at a $4 \%$ default threshold by the proteasome and immunoproteasome filters on at 5\% threshold (Singh and Raghava 2001).

MHC class I and II predictions were determined using the Immune Epitope Database (IEDB) (http://tools.immuneepit ope.org/main/). For prediction of CTL epitopes, "ctlpred" and ANN methods were used (48).

Probability of antigenicity was expected by VaxiJen software at http://www.ddg-pharmfac.net (Doytchinova and Flower 2007).

$\operatorname{IgE}$ epitopes and allergic properties were estimated at http://www.imtech.res.in/raghava/algpred/index.html by using AlgPred (Saha and Raghava 2006).

\section{Post-modification}

Serine, threonine, and tyrosine phosphorylation sites prediction was done using DISPHOS (http://www.dabi.templ e.edu/disphos/pred.html) (Iakoucheva et al. 2004) and NetPhos (http://www.cbs.dtu.dk/services/NetPhos/) (Blom et al. 1999). Kinase specific phosphorylation sites were determined by NetPhosK (http://www.cbs.dtu.dk/services/ NetPhosK/) (Blom et al. 2004). NetNGlyc (http://www.cbs. dtu.dk/services/NetNGlyc/) (Gupta and Brunak 2002) and GlycoEP (http://www.imtech.res.in/raghava/glycoep/submi t.html) were employed for $\mathrm{N}$-glycosylation sites prediction (Chauhan et al. 2013).

\section{Secondary and Tertiary Structure Prediction}

To predict secondary and tertiary structures of core and domain 1 of genotype 1a, SOPMA at (http://npsa-pbil. ibcp.fr/cgi-bin/npsa_automat.pl?page=npsa_sopma.html) (Geourjon and Deleage 1995), I-TASSER at (http://zhang lab.ccmb.med.umich.edu/I-TASSER) (Roy et al. 2010), PHYRE ${ }^{2}$ server at (http://www.sbg.bio.ic.ac.uk/ phyre 
2/html) (Kelley and Sternberg 2009), (PS) ${ }^{2}$-v2 Server at (http://ps2v2.life.nctu.edu.tw) (Chen et al. 2006) were employed. To evaluate the stereochemistry and quality of 3D structures Qmean at (http://swissmodel.expasy.org/ qmean/cgi/index.cgi) (Benkert et al. 2008) was used, and the Ramachandaran plot was mapped by Rampage (http:// mordred.bioc.cam.ac.uk/ rapper/rampage.php).

\section{The Signal Peptide Prediction}

The Signal peptide was predicted by "Signal-BLAST", and "SignalP 4.1 Server".

\section{Prediction of Epitopes Digestion: Peptide Cutter was Used to Determine Potential Cleavage Sites Cleaved by Proteases}

\section{Research Ethics}

All data were collected anonymously in accordance with legal requirements regarding data protection and medical confidentiality. Approval from the Faculty Human Research Ethics Committee (Shiraz University of Medical Sciences) was obtained before the commencement of the study.

\section{Results}

\section{Mutation and Phylogenic Tree}

By considering all submitted sequences in NCBI GenBank we could not find any sequences related to 2017.

Phylogenetic tree for all sequences was shown in Fig. 1. All 2006 sequences were placed in a cluster at the bottom of the tree, and a sequence of 2012 has a high similarity to KF218585.1 (2014). The majority of sequences were closer to $1 \mathrm{a}$ and $3 \mathrm{a}$ than other reference sequences.

All important mutation positions were listed in Table 2; the majority of mutations happened in 2013 and 2016 samples. No mutation was detected in $12,23,25,39,45$ positions.

\section{Protparam analysis}

Protparam results for domain 1 are listed in Table 3. Because of the high percentage of basic amino acids, domain 1 is a highly basic peptide (Theoretical pI: 12). The instability index, an estimate of the stability of a protein in a test tube, showed that domain 1 is an unstable peptide. Aliphatic index, a positive factor for the increase of thermostability of proteins, indicated that this peptide is a thermostable peptide. GRAVY is a hydropath city index and increasing

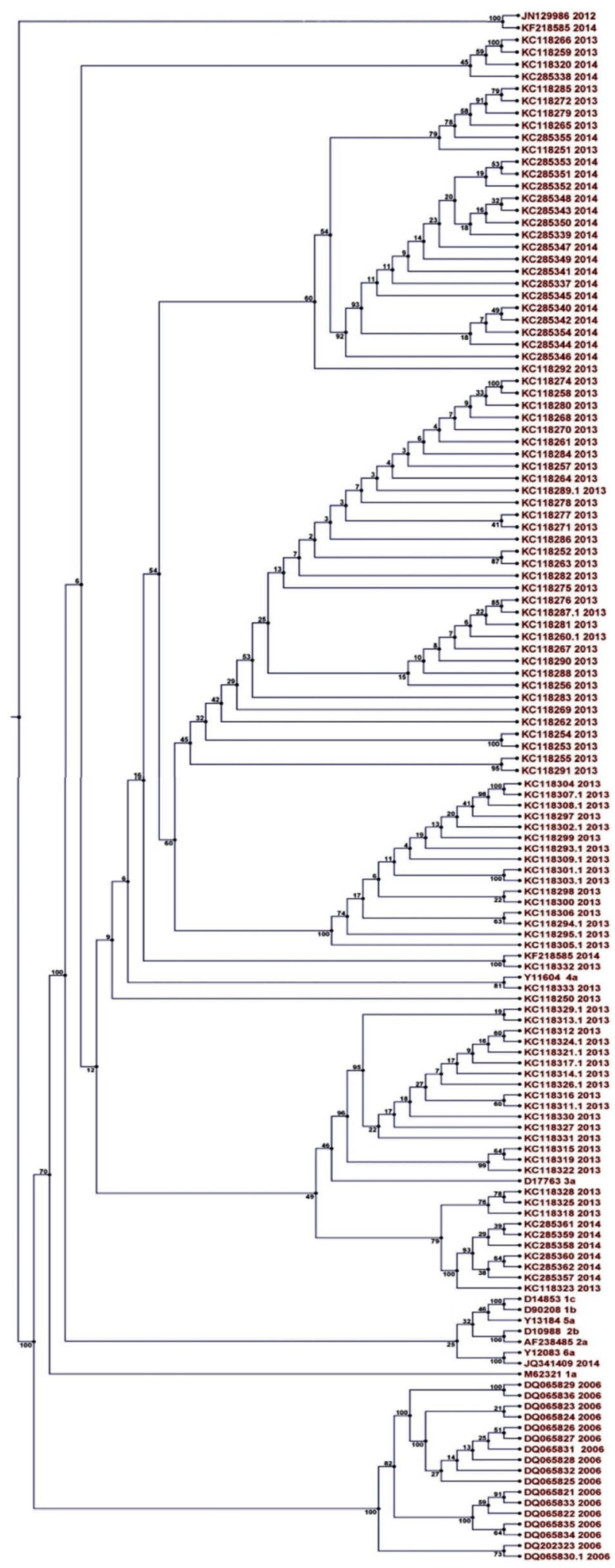

Fig. 1 Phylogenetic tree based on domain1 sequences and by using neighbor joining method. The phylogenetic tree was constructed by the NJ method. The numbers at the forks show the numbers of occurrences of the repetitive groups to the right out of 100 bootstrap samples. All used reference sequences were showed after accession numbers (1a, 1b, and etc.). Sequences were categorized in five major clusters 
Table 2 Frequency of all identified mutations in HCV-core domain1 sequences

\begin{tabular}{lllllll}
\hline & 2006 & 2012 & 2013 & 2014 & 2016 & Ref \\
\hline $11(\mathrm{~T})$ & - & - & $1(\mathrm{P}) 1.2 \%$ & - & $1 \mathrm{a}(\mathrm{N})$ \\
$12(\mathrm{~K})$ & - & - & - & - & - \\
$23(\mathrm{~K})$ & - & - & - & - & - \\
$25(\mathrm{P})$ & - & - & - & - & - & - \\
$39(\mathrm{R})$ & - & - & - & - & - \\
$45(\mathrm{G})$ & - & - & - & - & - \\
$49(\mathrm{~T})$ & $2(\mathrm{~V}) 11.7 \%$ & - & $2(\mathrm{P}) 2.4 \%, 5(\mathrm{~A}) 6.1 \%, 1(\mathrm{~V}) 1.2 \%$ & $1(\mathrm{~V}) 3.5 \%$ & $1(\mathrm{p}) 1.6 \%$ & - \\
$69(\mathrm{R})$ & - & - & - & - & - \\
$70(\mathrm{R})$ & $2(\mathrm{Q}) 11.7 \%$ & - & $3(\mathrm{Q}) 3.7 \%, 2(\mathrm{H}) 2.4 \%, 1(\mathrm{P}) 1.2 \%$ & $4(\mathrm{Q}) 14.3 \%$ & $25(\mathrm{Q}) 42.3 \%, 1(\mathrm{H}) 1.6 \%$ & $3 \mathrm{a}, 6 \mathrm{a}(\mathrm{Q})$ \\
$74(\mathrm{R})$ & - & - & - & - & - \\
$78(\mathrm{Q})$ & - & - & - & $1(\mathrm{R}) 3.5 \%$ & & $2 \mathrm{a}, 2 \mathrm{~b}(\mathrm{~K})$ \\
$90(\mathrm{G})$ & - & - & $1(\mathrm{~L}) 1.2 \%, 1(\mathrm{~S}) 1.2 \%$ & - & - \\
$91(\mathrm{C})$ & $2(\mathrm{M}) 11.7 \%$ & - & $13(\mathrm{M}) 16.4 \%, 3(\mathrm{~L}) 3.7 \%, 1(\mathrm{~F}) 1.2 \%$ & - & \\
$102(\mathrm{G})$ & - & - & - & - & $43(\mathrm{M}) 72.8 \%, 7(\mathrm{~L}) 11.8$ & $1 \mathrm{~b}(\mathrm{M}) ; 2 \mathrm{a}$ and 5a (L) \\
110 & $8(\mathrm{~T}) 47 \%, 9(\mathrm{~N}) 53 \%$ & - & $23(\mathrm{~N}) 28.4 \%, 5(\mathrm{~S}) 6.1 \%, 53(\mathrm{~T}) 65.4 \%$ & $18(\mathrm{~T}) 64.3 \%$, & $\mathrm{N}(10) 17 \%$ & $5 \mathrm{a}(\mathrm{S})$ \\
& & & & $8(\mathrm{~N}) 28.57 \%$ & & $1 \mathrm{~b}, 1 \mathrm{a}, 2 \mathrm{~b}(\mathrm{~T}) ; 1 \mathrm{c}(\mathrm{S}) ;$ \\
& & & & $4 \mathrm{a}, 3 \mathrm{a}, 6 \mathrm{a}, 2 \mathrm{a}$, \\
\hline
\end{tabular}

The majority of mutations happened in amino acid residues 49, 70, 91, 110

positive score indicates a greater hydrophobicity, so this peptide is a hydrophilic peptide.

\section{ProtScale Analysis}

Hydropathicity analysis by Kyte J. and Doolittle R.F. method showed that the major part of the peptide had a negative score; the maximum hydropath city score was on aa34 (valin) and the minimum hydropath city score was on aa 14 (asparagine).

Amino acids flexibility predicted by Bhaskaran R Ponnuswamy P.K method indicated that the maximum flexibility was around amino acid 58 (proline) and the minimum was around aa 95 (glycine).

Transmembrane (TM) tendency calculated by Zhao, G., London E. method, showed that the major part of peptide had a negative score, and the maximum transmembrane tendency was on aa34 (valine) and the minimum was on aa10 (lysine).

Peptide polarity predicted by Grantham R method showed that the maximum polarity was on amino acid 12 and 13 (lysine and arginine) and the minimum polarity was on aa 34 (valine).

\section{B-Cell Epitopes Prediction}

http://www.immuneepitope.org online software:

Chou and Fasman Beta-Turn Prediction, which is based on the rationale for predicting turns to predict antibody epitopes, showed one high score region, 99-112.
Emini Surface Accessibility Prediction, which is based on surface accessibility scale, showed two high score positions (4-20 and 49-61).

Karplus and Schulz flexibility scale was used for B-cell prediction; this method is based on mobility of protein segments on the basis of the known temperature B factors of the a-carbons of 31 proteins of known structure. Results demonstrated two positions with the highest score (50-60 and 5-12).

Kolaskar \& Tongaonkar Antigenicity method is based on physicochemical properties of amino acid residues and their frequencies of occurrence in experimentally known segmental epitopes to predict antigenic determinants on protein. Results showed five positions of 20-39, 43-49, 63-69, 78-85, and 93-101.

Parker Hydrophilicity Prediction method is based on peptide retention times during high-performance liquid chromatography (HPLC) on a reversed-phase column. By this method, two regions were found: 9-16, 51-57.

Linear B-cell epitopes were determined using BepiPred. This method is based on a combination of a hidden Markov model and a propensity scale method. Three regions (1-25, 51-84, and 102-116) were founded by BepiPred analysis.

\section{Bcepred Results}

For a combination of all physicochemical properties (hydrophilicity, flexibility/mobility, accessibility, polarity, exposed surface, and turns) for linear B-cell epitope prediction based on physicochemical properties on a non-redundant dataset: 
Table 3 Domain 1 physicochemical properties computed by "Protparam"

\begin{tabular}{|c|c|c|}
\hline Amino acid composition & Number & Percentage (\%) \\
\hline \multicolumn{3}{|l|}{ Number of amino acids: 117} \\
\hline \multicolumn{3}{|l|}{ Molecular weight: 13320.2} \\
\hline \multicolumn{3}{|l|}{ Theoretical pI: 12.05} \\
\hline Ala (A) & 4 & 3.40 \\
\hline $\operatorname{Arg}(\mathrm{R})$ & 21 & 17.90 \\
\hline Asn $(\mathrm{N})$ & 5 & 4.30 \\
\hline Asp (D) & 2 & 1.70 \\
\hline Cys (C) & 1 & 0.90 \\
\hline Gln $(\mathrm{Q})$ & 6 & 5.10 \\
\hline Glu (E) & 3 & 2.60 \\
\hline Gly (G) & 16 & 13.70 \\
\hline Ile (I) & 2 & 1.70 \\
\hline Leu (L) & 6 & 5.10 \\
\hline Lys (K) & 7 & 6.00 \\
\hline Met (M) & 1 & 0.90 \\
\hline Phe $(F)$ & 1 & 0.90 \\
\hline Pro $(\mathrm{P})$ & 17 & 14.50 \\
\hline $\operatorname{Ser}(S)$ & 7 & 6.00 \\
\hline $\operatorname{Thr}(\mathrm{T})$ & 6 & 5.10 \\
\hline $\operatorname{Trp}(\mathrm{W})$ & 5 & 4.30 \\
\hline $\operatorname{Tyr}(\mathrm{Y})$ & 3 & 2.60 \\
\hline $\operatorname{Val}(\mathrm{V}) 4$ & & 3.40 \\
\hline Total number of negatively charged residues $(\mathrm{Asp}+\mathrm{Glu})$ & 5 & \\
\hline Total number of positively charged residues (Arg + Lys) & 28 & \\
\hline \multicolumn{3}{|l|}{ The estimated half-life is } \\
\hline Mammalian reticulocytes, in vitro & $30 \mathrm{~h}$ & \\
\hline Yeast, in vivo & $>20 \mathrm{~h}$ & \\
\hline Escherichia coli, in vivo & $>10 \mathrm{~h}$ & \\
\hline The instability index (II) & 77.69 unstable & \\
\hline Aliphatic index & 40 & \\
\hline Grand average of hydropathicity (GRAVY) & -1.424 & \\
\hline
\end{tabular}

Table 416 meric conserved B-cell epitopes regions in $\mathrm{HCV}$-core domain1, predicted by ABCpred online software

\begin{tabular}{llcl}
\hline Rank & Sequence & Position & Score \\
\hline 1 & QPGYPWPLYGNEGCGW & $78-93$ & 0.92 \\
2 & TRKTSERSQPRGRRQP & $49-64$ & 0.9 \\
3 & MSTNPKPQKKNKRNTN & $1-16$ & 0.89 \\
4 & PIPKARRPEGRTWAQP & $64-79$ & 0.86 \\
4 & GSRPSWGPTDPRRRSR & $102-117$ & 0.86 \\
\hline
\end{tabular}

Using bcepred online software, three regions (4-22, $47-59$, and 109-115) with the highest combined score were found.

Five 16 meric conserved regions (78, 49, 1, 64 and 102) were found by ABCpred prediction Server (Table 4).

\section{VaxiJen Prediction}

According to a predefined cutoff of VaxiJen program, domain 1 was confirmed as a probable antigen (model: virus and threshold: 0.4).

\section{IgE Epitopes}

The prediction of allergenic proteins by mapping of $\operatorname{IgE}$ epitope, SVM, and hybrid methods showed that domain 1 was not an allergen protein.

\section{T Cell-Epitopes}

Regarding $\mathrm{T}$-cell responses against $\mathrm{HCV}$, previous researches found some hosts' human leukocyte antigen 
Table 5 HLA predicted epitopes in HCV-core domain1 sequence (genotype 1a) for HLA's that were determined by previous researches in Iranian patients

\begin{tabular}{ll}
\hline HLA types & Epitopes positions \\
\hline HLA-A1 & 1 10 \\
HLA-A2 & $29-44,77-85$ \\
HLA-A3 & $2-10,29-59,96-104$ \\
HLA-B*3501 & $6-14,27-35,41-49,57-65,78-91,99-116$ \\
HLA-B*3801 & $29-37,77-85,89-97$ \\
HLA-Cw*0401 & $23-37,58-65,78-93$ \\
HLA-Cw*0702 & $27-35,73-86$ \\
HLA-DQA1*05:01 & $2-16,13-27$ \\
HLA-DQA1*0201 & NO \\
HLA-DQB1*0602 & $2-16,17-31,102-116$ \\
HLA-DQB1*0301 & $96-104$ \\
HLA-G: HLA-G*01:01, & $4-16,8-21,22-33,66-79,100-112$ \\
HLA-G*01:02 & \\
HLA-DRB1*0301 & $96-104$ \\
HLA-DRB1*0305 & $96-104$ \\
HLA-DRB1*0309 & $96-104$ \\
HLA-DRB1*0701 & No \\
HLA-DRB1*11 & $34-42$ \\
\hline
\end{tabular}

Table 6 CTL epitopes in HCV-core domain 1; the high score epitopes are displayed

\begin{tabular}{lllll}
\hline Peptide Rank & Position & Sequence & Score & Prediction \\
\hline 1 & $48-56$ & ATRKTSERS & 1 & Epitope \\
2 & $80-88$ & GYPWPLYGN & 1 & Epitope \\
3 & $2-10$ & STNPKPQKK & 0.99 & Epitope \\
\hline
\end{tabular}

(HLA) alleles associations with HCV infection in Iranian patients. We found several epitopes of HLA's shown in Table 5.

Some studies found both CD4 helper and CD8 CTL responses against $\mathrm{HCV}$ infection. ctlpred found several epitopes for CTL (Table 6).

\section{Postmodification}

Prediction of serine, threonine, and tyrosine phosphorylation sites by DISPHOS showed one position (116) in domain1.

By "NetPhos" software we found 10 phosphorylation sites (Fig. 2), 6 sites for serine (53, 56, 99, 103, 106, and 116) 3 sites for threonine $(15,49$, and 52) and one site for tyrosine (86).

NetPhosK results determined four phosphorylation sites, three threonine amino acids $(3,15$, and 49) for protein kinase $\mathrm{C}$ and one serine (116) for protein kinase A. No glycosylation site was found by NetNGlyc and GlycoEP.

\section{Secondary and Tertiary Structure Prediction}

Secondary structure prediction for core and domain 1 by using SOMPA software was summarized in Table 7 and Fig. 3.

SOMPA showed there was no alpha helix structure in domain 1 and the major part of it was the random coil. But the combination of (PS $)^{2}-\mathrm{v} 2$ and $\mathrm{PHYRE}^{2}$ showed there was an alpha helix structure in $8-15$ region (Figs. 4, 5). All programs displayed extended strand in the 29-36 region.

3D structures were determined by all three online software but only structures predicted by I-TASSER were

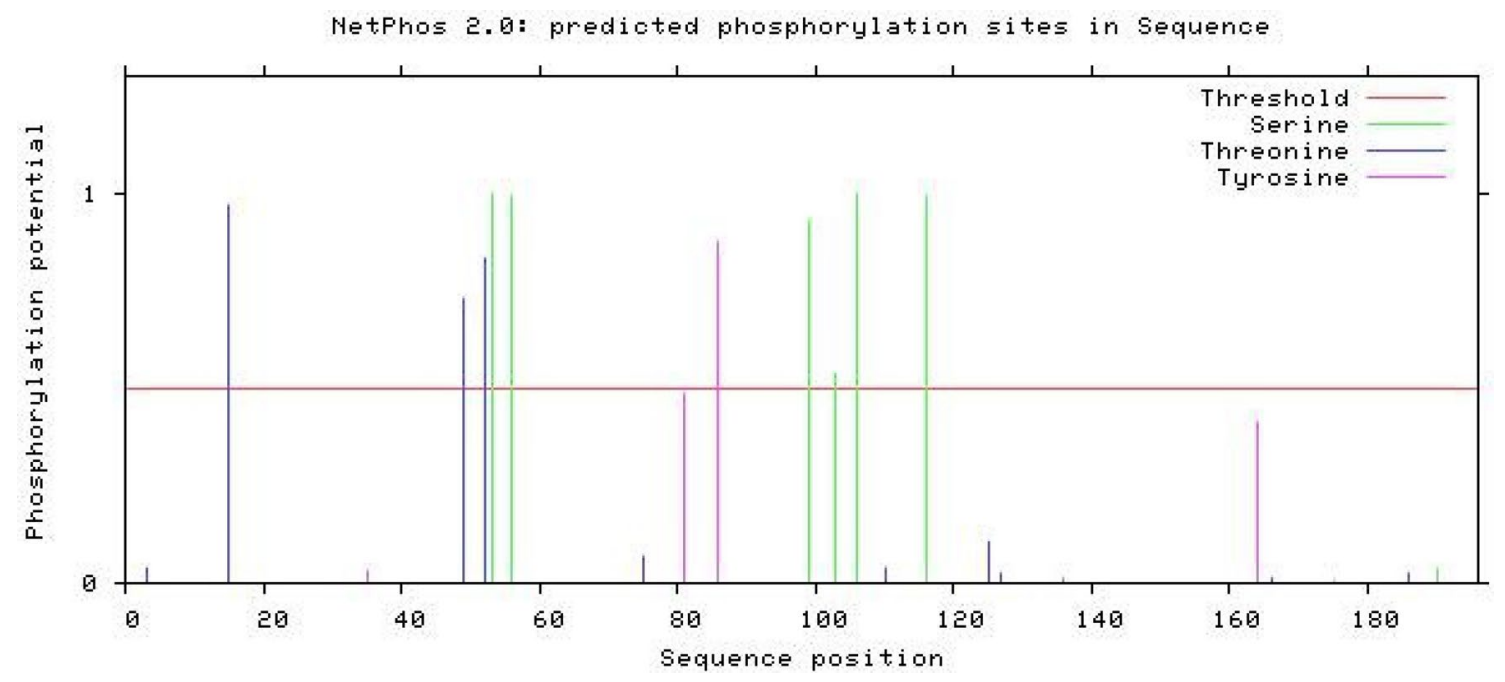

Fig. 2 Phosphorylation sites prediction for domain 1 using "NetPhos" online software. Green lines indicate 6 sites for serine, blues lines show 3 sites for threonine, and one purple line shows tyrosine. All sites with scores above the threshold of 0.5 were considered as phosphorylation sites 
Table 7 Percentage of secondary structures in core and domain1

\begin{tabular}{lllll}
\hline & Alpha helix $(\mathrm{Hh})$ & Extended strand $(\mathrm{Ee})$ & Beta turn $(\mathrm{Tt})$ & Random coil $(\mathrm{Cc})$ \\
\hline Core & $39,20.42 \%$ & $25,13.09 \%$ & $14,7.33 \%$ & $113,59.16 \%$ \\
Domain 1 & NO & $19,16.24 \%$ & $10,8.55 \%$ & $88,75.21 \%$ \\
\hline
\end{tabular}

Fig. 3 Secondary structure prediction using SOMPA. Red region is extended strand, blue is the alpha helix, green is beta turn, and purple is the random coil. The majority of core structure belongs to random coil

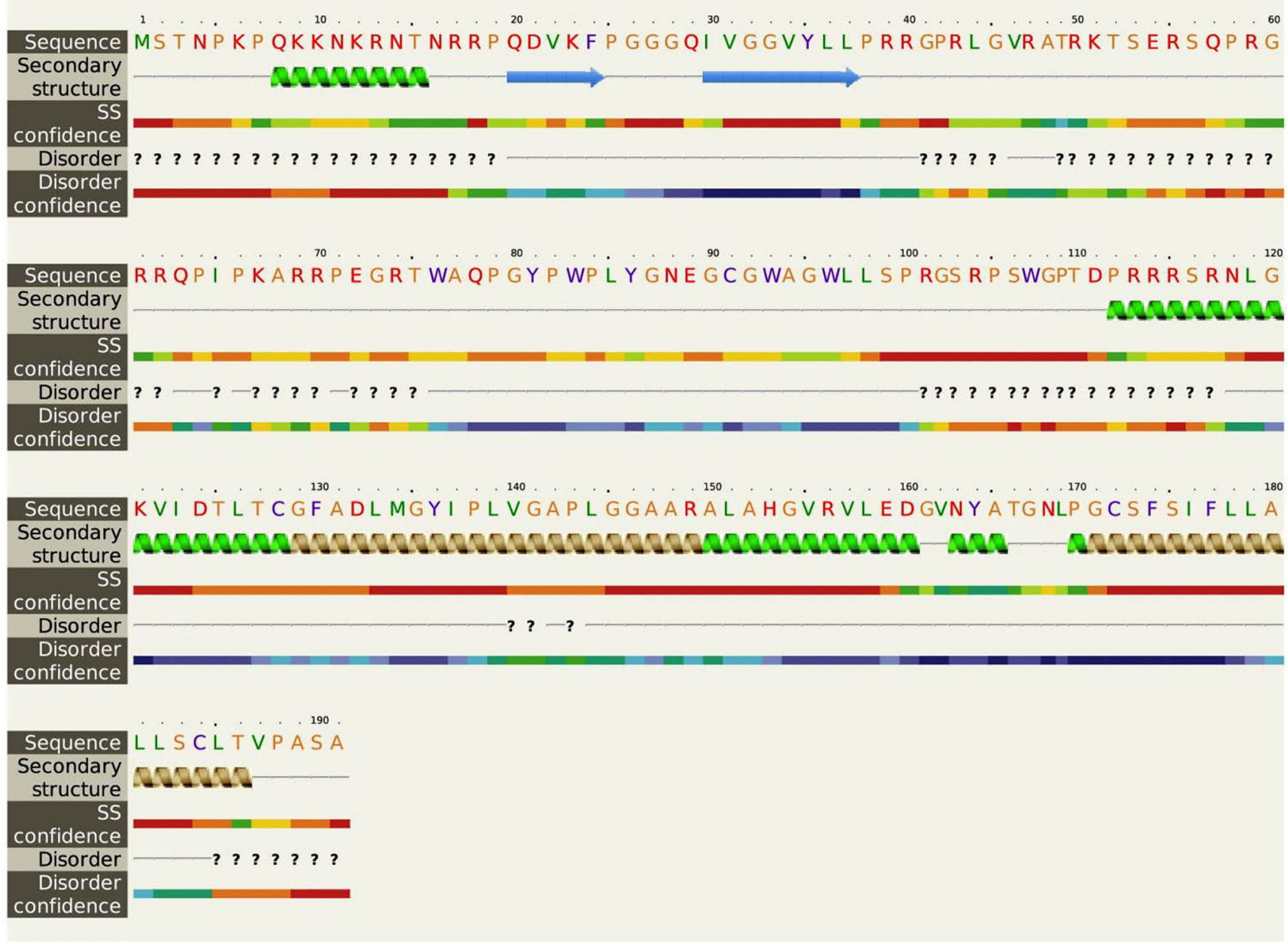

Fig. 4 Secondary structure prediction using PHYRE2. The result of this tool shows that the majority of the core structure (40\%) is alpha helix which is indicated with green helix, also the confidence keys of the predicted structure for these regions are high

reliable. Final structures (Figs. 6, 7) were validated by Qmean. QMEANscore and Z-score for calculated for core were 0.242 and -5.43 . The scores were not satisfactory but at least provided an overview of the core protein structure. QMEANscore and Z-score for domain 1 were 0.61 and -1.24 confirming the quality and reliability of the predicted structure.

Ramachandran plot was assessed by RAMPAGE, and percentages of the favoured region, allowed region, and outlier region for core were $63.0 \%, 27.5 \%$, and $9.5 \%$ respectively 


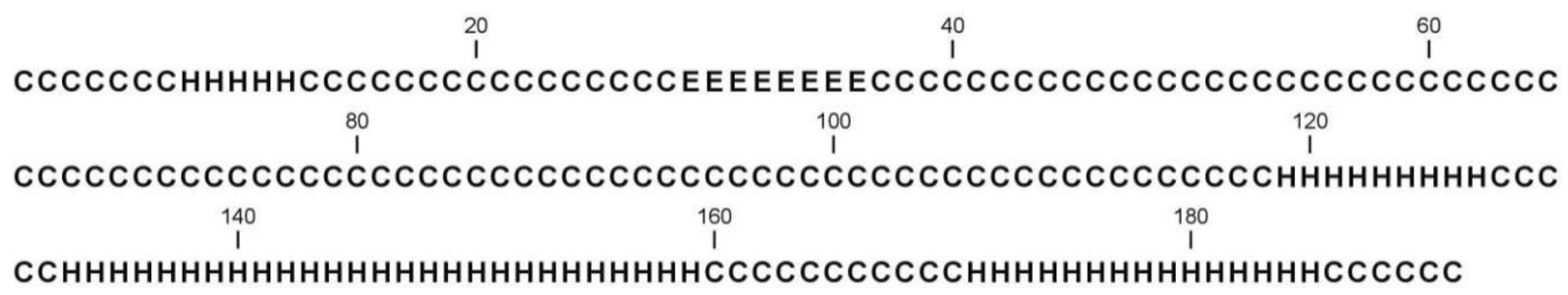

Fig. 5 Secondary structure prediction using (PS) ${ }^{2}$-v2. $C$ coil, $H$ helix, and $E$ extended strand. The majority of core structure contains coil structure

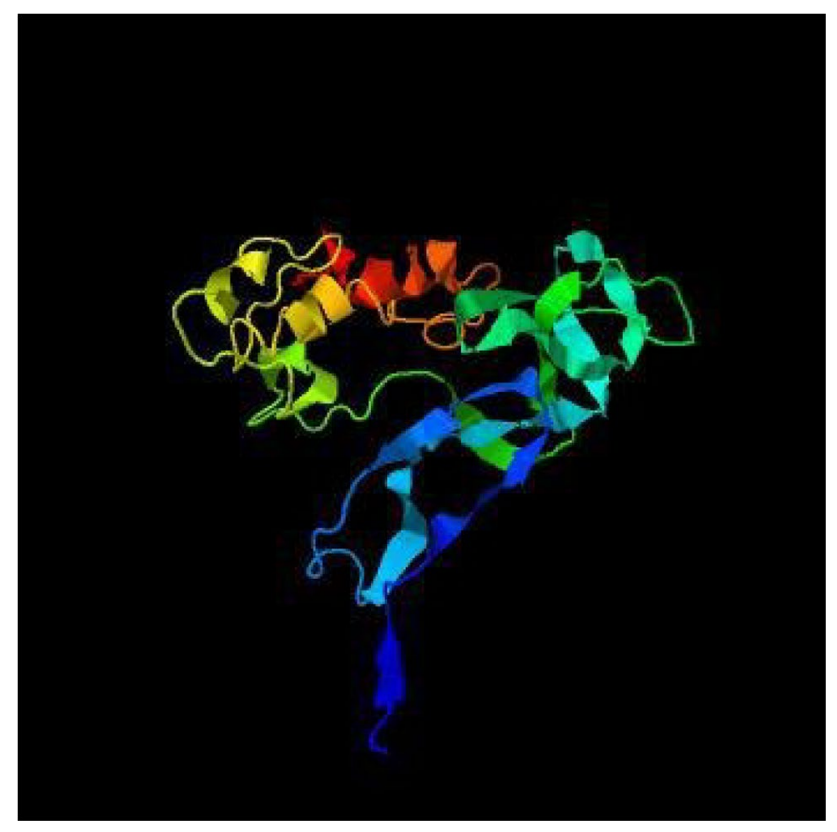

Fig. 6 3D structure of the core protein using "I-TASSER" program. The selected model had the highest $\mathrm{C}$ score and it was qualified by "Qmean"

(Fig. 8). RAMPAGE results for domain1 showed $61.7 \%$ of residues in favored region and 24.3 in allowed region (Fig. 9). Figure 10 showed the showed T cell and B-cell epitopes on the surface of the core protein.

\section{Core Signal Peptide}

Both online tools "Signal-BLAST" and "SignalP 4.1 Server" were not able to predict any signal peptide for core protein.

\section{Cleavage Sites Prediction}

The results of "PeptideCutter" prediction were summarized in Table 8. The prediction was done for all the predicted epitopes. According to the results, the antigenic epitopes that had the lower number of cleavage positions for enzymes were more potential for $\mathrm{B}$ cell or $\mathrm{T}$ cell epitopes.

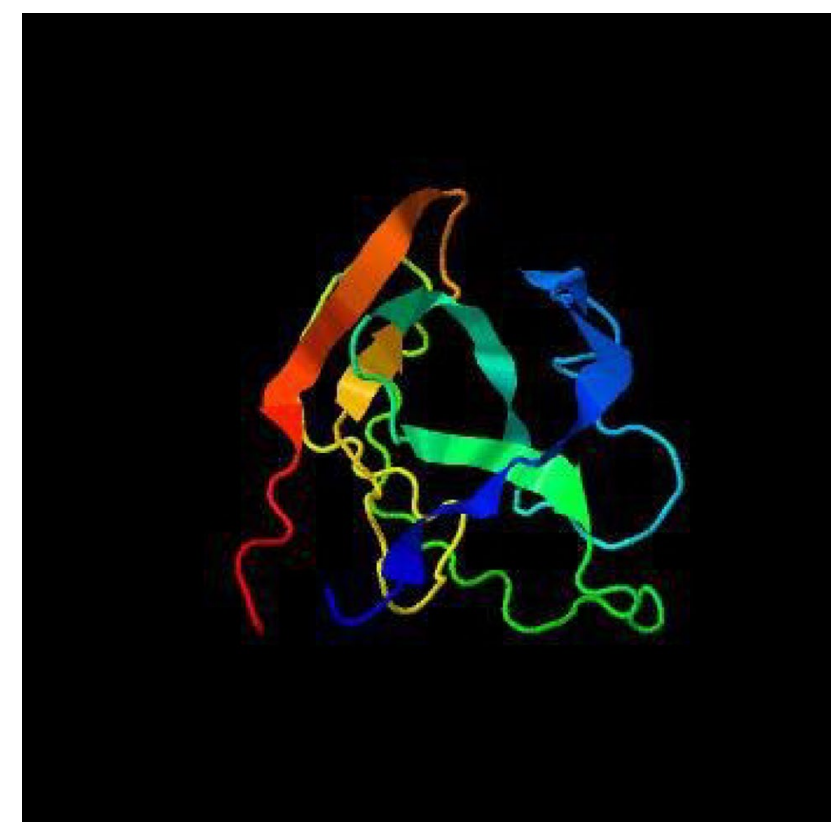

Fig. 7 3D structure of domain1 using I-TASSER program. The selected model had the highest $\mathrm{C}$ score and it was qualified by "Qmean"

\section{Discussion}

Although emerging bacterial viral diseases have caused great catastrophes in human history which can affect from a small and localized group to millions of people across continents, several vaccine and therapies have been introduced to control them (Dehghani et al. 2014, 2013).

Fishman et al. (2009) using multivariable logistic regression models ,found $10 \mathrm{HCV}$-core gene polymorphisms extensively associated with increased HCC risk (36G/C, 209A, 271C/U, 309A/C, 384U, 408U, 435A/C, $465 \mathrm{U}, 481 \mathrm{~A}, 546 \mathrm{~A} / \mathrm{C})$ and one significantly linked with decreased HCC risk (78U). Mentioned mutations related to change in domain 1 amino acid sequence: N11S/T, K12Silent/N, A25V, G69S, Q70R, M91L, and L102P. All current amino acid changes decreased HCC risk except A25V (78U) (Fishman et al. 2009). 


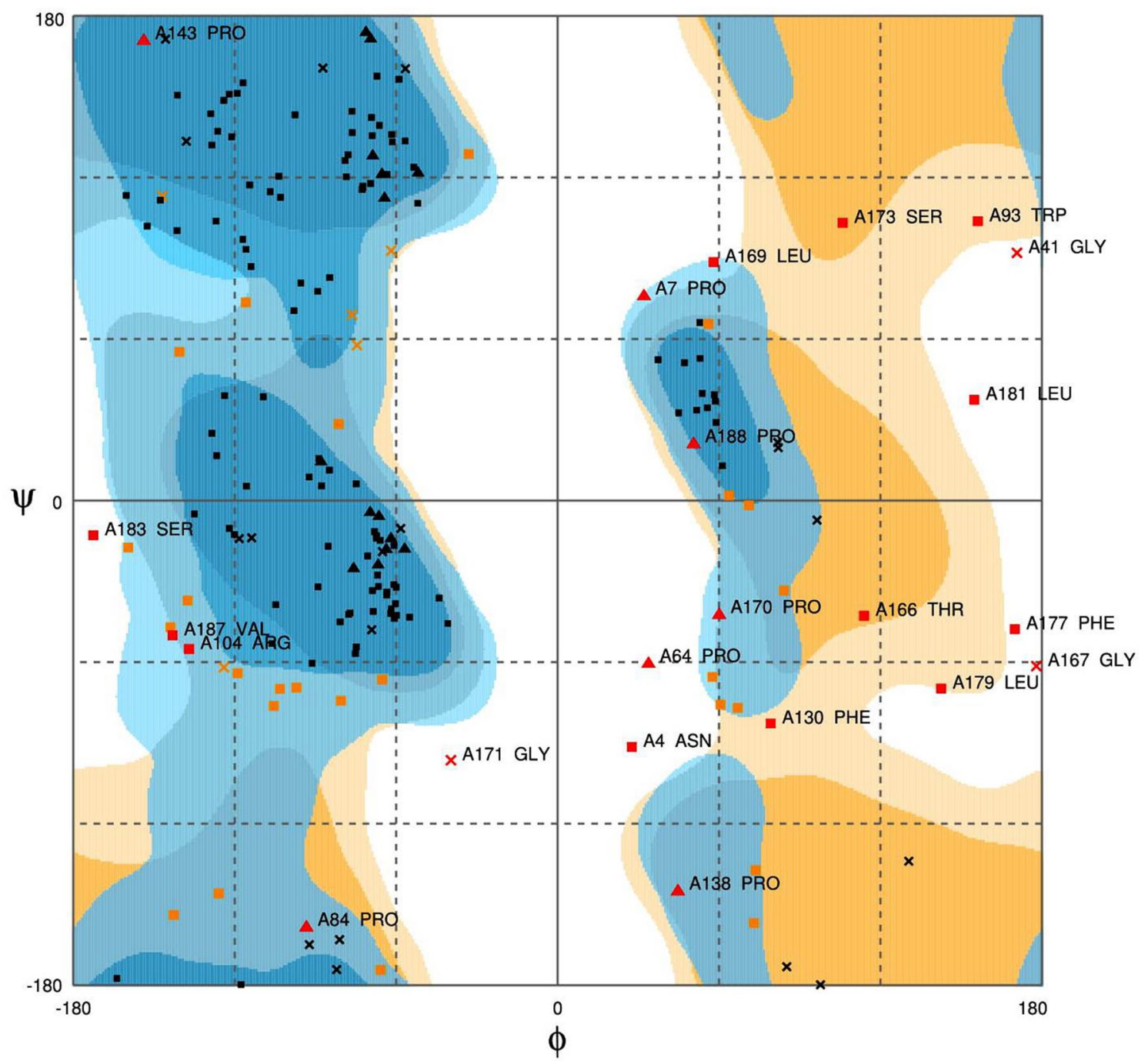

Fig. 8 Ramachandran plot was used to visualize energetically allowed regions for backbone dihedral angles $\psi$ against $\phi$ of amino acid residues in modeled protein structure (LCC model) for tertiary structure of core protein by RAMPAGE; the majority of amino acids residues were in favored region (119 amino acids) and allowed region (52 amino acids)

Akuta et al. (2007) employed PCR for detecting substitutions of aa 70 and aa 91 in HCV-core gene of genotype $1 \mathrm{~b}$ by using the mutation-specific primer as an important predictor of hepatocarcinogenesis. For wild samples, aa 70 was arginine $(\mathrm{R})$ and aa 91 was leucine $(\mathrm{L})$ but for mutant aa 70 was glutamine $(\mathrm{Q}) /$ histidine $(\mathrm{H})$ and aa 91 was methionine (M) (Akuta et al. 2007).

Also, Furui et al. (2011) identified aa 70 and aa 91 substitutions among Japanese volunteer blood donors (Furui et al. 2011).

In terms of aa 70 substitutions, we recognized 2 glutamine substitutions in 2006 sequences and 3 glutamine, 2 histidines, one proline in 2013 sequences; also 4 glutamine substitutions in 2014 sequences, and 25 glutamine, and 1 


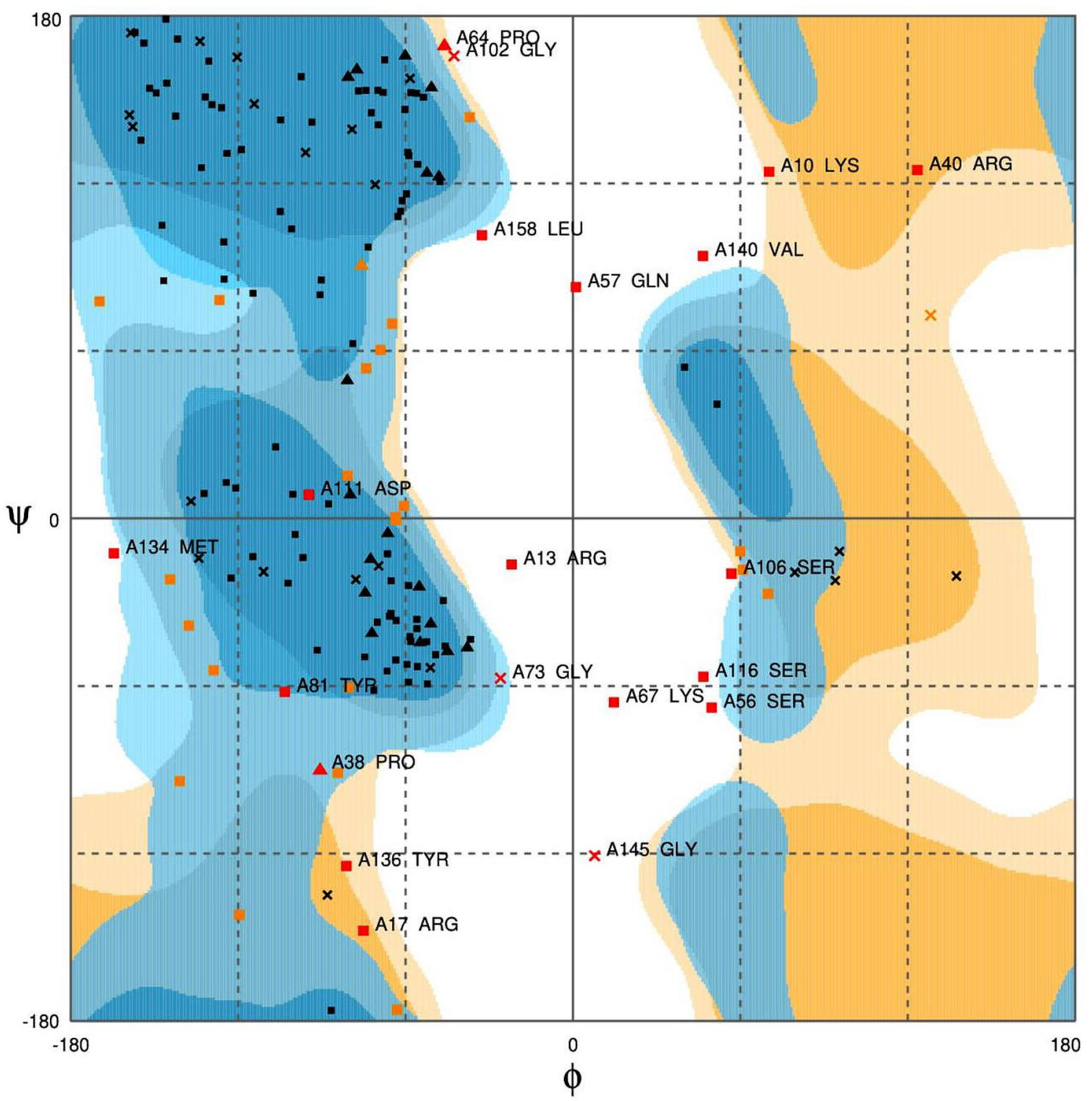

Fig. 9 Ramachandran plot was used to visualize energetically allowed regions for backbone dihedral angles $\psi$ against $\phi$ of amino acid residues in modeled protein structure (LCC model) for tertiary structure

histidine in 2016. We found several methionine residues in aa 91 in 2006, 2014, and 2016.

Ogata et al. (2002) compared sequences of the core protein of Subtype $1 \mathrm{~b} \mathrm{HCV}$ strains obtained from patients with and without $\mathrm{HCC}$ and found some amino acid mutation sites (Ogata et al. 2002). K23Q, Q70R, and T110M substitutions were found by Ogata et al. (2002). In comparison with our results, in all sequences, aa 23 was $\mathrm{K}$, in the majority of sequences aa 70 was $\mathrm{R}$ and in 34 sequences it was $\mathrm{Q}$. In aa 110 we did not find any methionine (Ogata et al. 2002).

Akuta et al. (2010) confirmed the role of Gln70 (or His70) in the efficacy of triple therapy and sustained a virological response, the patient with both genotype non-TT and of domain 1 by RAMPAGE; majority of amino acids residues were in favored region (71 amino acids) and allowed region (28 amino acids)

Gln70 (His70) had the worst sustained virological response. Also, Akuta et al. (2011) by following up twenty-six patients determined the role of Gln70 (His70) substitution in the development of HCC They suggested detection of aa substitutions in the core region before antiviral therapy (Akuta et al. 2010, 2011).

Alestig et al. (2011) showed substitution in aa 70 of the core was related to treatment response, but that was less important than IL28B polymorphism. In our study, 37 sequences had Gln70 (or His70) substitution (Alestig et al. 2011).

Tokita et al. (2000) approved the role of HCV-core region (Thr49Pro) to reduce the fluorescence enzyme immunoassay 
Fig. 10 A: the position of the B-Cell epitopes (yellow region) on core tertiary structure and B: the T-cell epitopes (yellow region) on core $3 \mathrm{D}$ structure

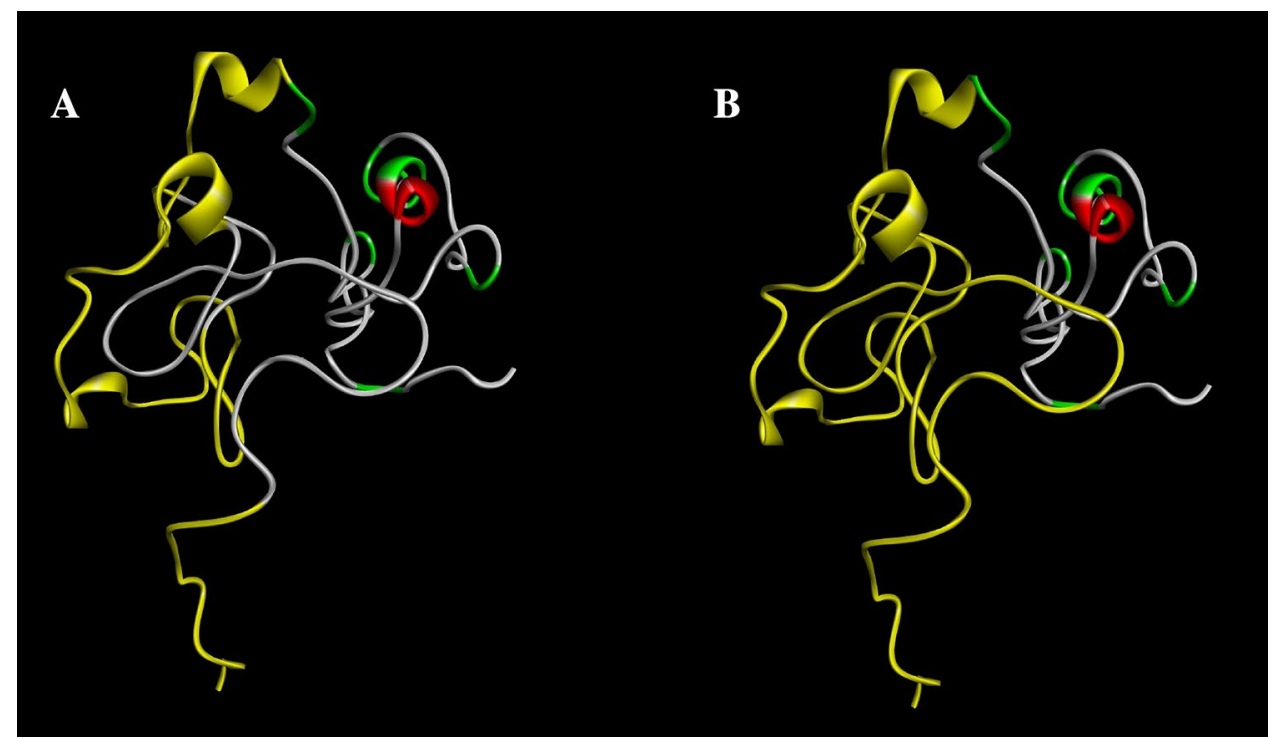

(FEIA) sensitivity. We found 2 sequences in 2013 and one in 2016 with T to P substitutions (Tokita et al. 2000).

Findings of Horie et al. (1999) indicated that alteration from glycine to serine at core codon 45 was dominant in noncancerous liver portions rather than in cancerous liver portions and sera from HCC patients (Horie et al. 1999). Our results did not show any glycine to serine mutation in aa 45 and in all sequences, it was glycine.

Idrees and Ashfaq (2013) by using molecular docking software, reported interactions of amino acid residues arginine 149, arginine 39, arginine 74, and arginine 78 in HCVcore protein and Leu44, Ala71, Ser76 and Pro97 in CXCL6. This finding clues to understanding HCV pathogenesis. Any change in these positions can relate to HCV Infection and HCC. Our results showed no alteration in aa 39 and 74, and in aa 78 just one sequence was glutamine to arginine (Idrees and Ashfaq 2013).

Using a combination of predicted B-cell antibody epitopes by all methods on the immune epitope website and also considering bcepred and $\mathrm{ABC}$ pred prediction, we could define three major epitopes (4-20, 50-60, and 100-112) for domain 1.

Ferroni et al. (1993) by using the algorithm of Jameson and Wolf identified four epitopes in HCV-core protein (7-21, 31-45, 49-63, and 99-113).

Harase et al. (1995) analyzed the response to HCV-core protein in mice and found a major B cell epitope (21-40).

Pirisi et al. (1995) analyzed Sera from $97 \mathrm{HCV}$ infected patients and found three 15-mer peptides as antigens in an enzyme immunoassay. They concluded that anti-R15P (50-64, RKTSERSQPRGRRQP) as a potent antigen might help to identify a subgroup at higher risk to develop HCC (Pirisi et al. 1995).
Also, a study on HCV positive blood donor by Lechmann et al. (1996) determined a region (aa 1-24) of domain1 that bound the antibodies from the sera of all patients and showed a great potential for detection of HCV infection by using serological B-Cell responses tests.

Comparison of our results with previous studies revealed that all predicted epitopes in our research have a good potential for future studies of the immune response against $\mathrm{HCV}$ infection, and are useful for recognition of all kinds of $\mathrm{HCV}$ infections.

Gededzha et al. (2014) used several bioinformatics tools to predict HLA class I and HLA class II in HCV genotype 5a. They found three T-cell epitopes of NS3, NS4B, and NS5B.

Some HLA class II alleles were found in Iranian patients by Samimi-Rad et al. (2015); DRB1*0301, DQA1*0501, DQB1*0201, DRB1*1101, and DQB1*0301 were demonstrated in patients with HCV clearance, and DRB1*0701, DQA1*0201, DQB1*0602, DRB1*0301, DRB1*11, and DQB1*0201 occurred more frequently in chronic patients (Samimi-Rad et al. 2015).

Khorrami et al. (2015) found a relationship between HLA-G, IL-10, and response to combined therapy in HCV positive patients. They concluded that HLA-G, and IL-10 have a significant role in response to therapy with IFN- $\alpha 2 \alpha$ and ribavirin.

Also, HLA-A01 and HLA-B38 were determined as important alleles associated with Peg-IFN plus ribavirin therapy in Egyptian patients by Farag et al. (2013).

Pourhassan et al. (2014) found several HLA alleles associated with HCV in Iranian patients (2011-2013). A2, A3, B35, B38, BW4, CW4and CW7 were the most frequent alleles found by this group. 


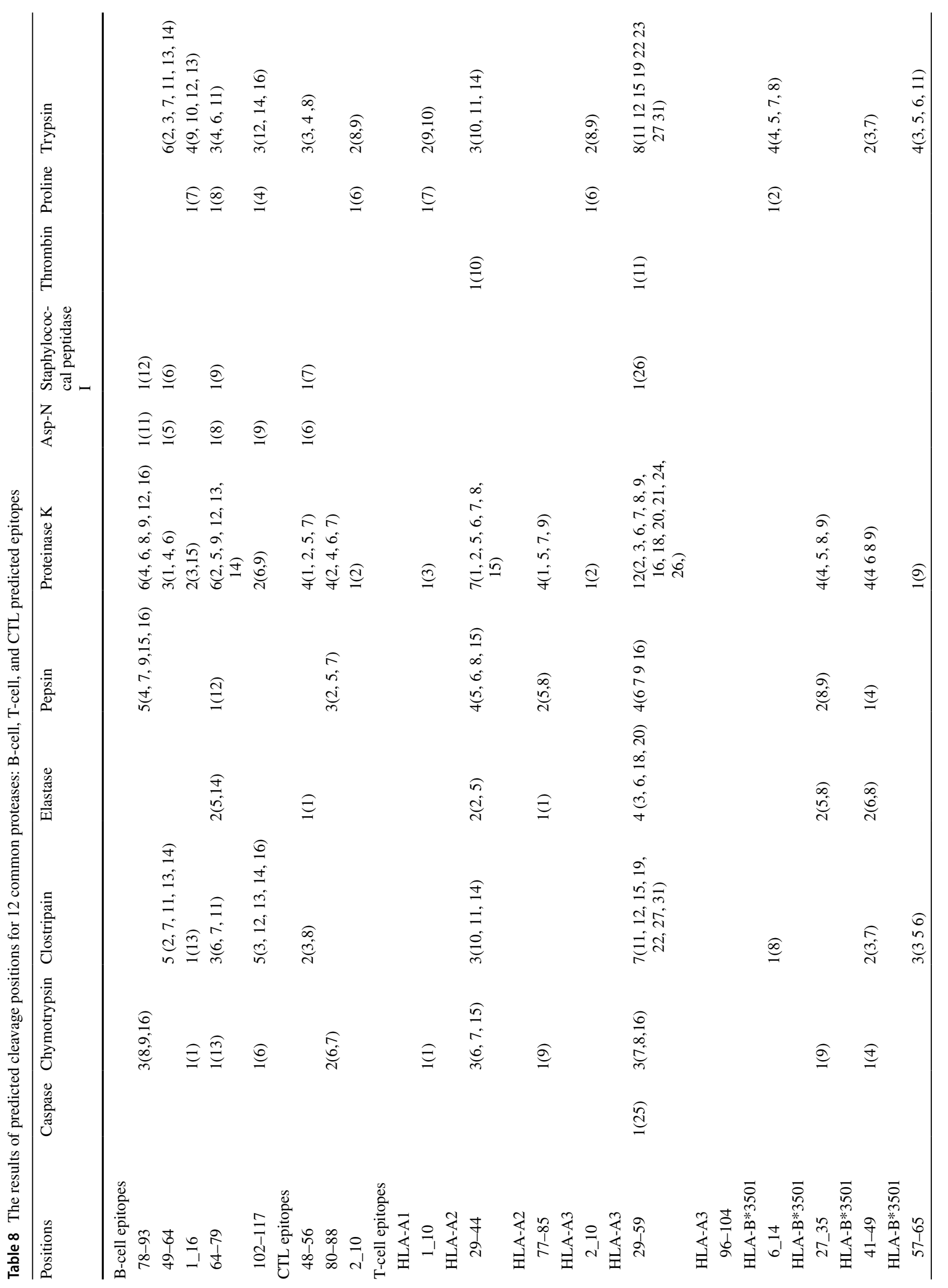




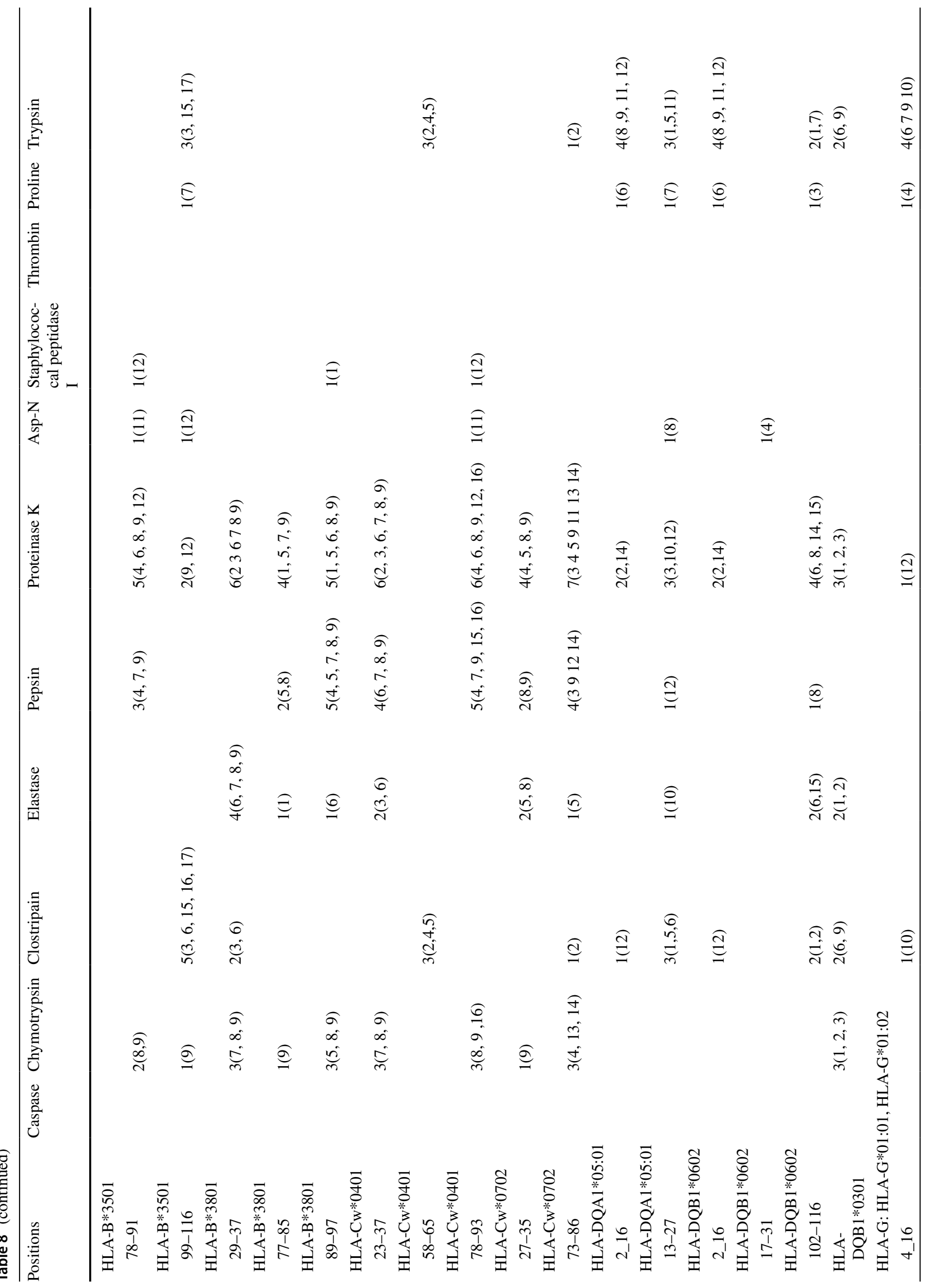




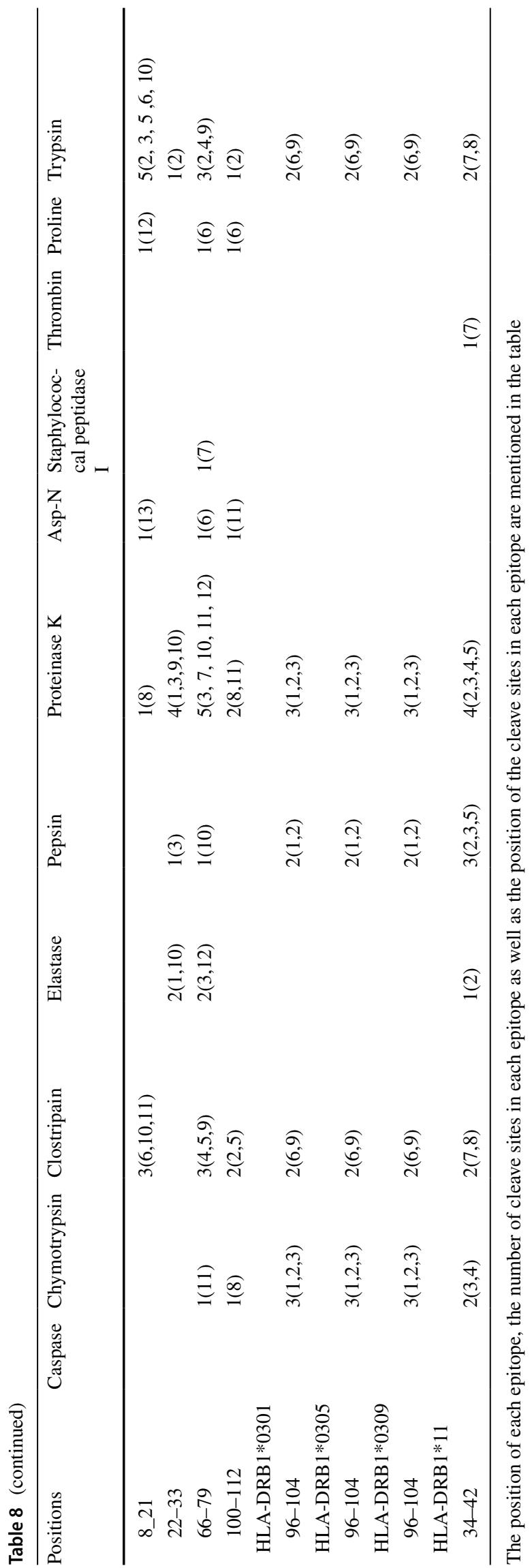

In accordance with the above-mentioned studies, we collected HLA alleles associated with HCV infection, and by employing in-silico analysis we established numerous T-cell epitopes for domain1 that can be helpful for future studies to design effective vaccine against $\mathrm{HCV}$ genotype $1 \mathrm{a}$, and can provide benefit data for better understanding the role of domain 1 in immune response.

Many researchers have proved broader CTL responses to HCV infection and the usefulness of CTL epitopes mapping to develop therapeutic interventions or vaccines (Sabet et al. 2014; Saeedi et al. 2014; Jazayeri and Carman 2005; Arashkia et al. 2011). In our research, we utilized reliable software to predict CTL epitopes and extracted data that can be useful for vaccine development studies.

By considering results of phosphorylation sites prediction by 3 programs, we concluded that 3 sites $(15,49$, and 116) were the main phosphorylation sites in domain 1. Amino acid 116 is a serine that located in Arg-Arg-ArgSer-Arg region; this region was similar to the usual target sequence for protein kinase A [Arg-Arg-X-Ser/Thr-X]. Two threonine amino acid residues $(15,49)$ were calculated as protein kinase $\mathrm{c}$ target sites where this kinase acts through the phosphorylation of hydroxyl groups of amino acid residue. Previous studies indicated that core protein is phosphorylated by PKA and PKC.

Core phosphorylation regulates the suppressive activity of $\mathrm{HCV}$-core protein on $\mathrm{HBV}$ gene replication and expression. Also, it has been shown that phosphorylation in core relates to the nuclear localization of the core protein. They demonstrated three serine residues (Ser-53, Ser-116, and Ser-99) as the potential phosphorylated sites in core protein, that were similar to NetPhos software results in our research (Yassin 2001; Shih et al. 1995; Lu and Ou 2002).

Secondary structure prediction indicated that the majority of domain 1 was the random coil, and all B-cell epitopes and important mutations placed on random coil structure.

Tertiary structures were designed by three significant and reliable online programs, but just one of them provided a reliable and high-quality protein structure model for domain1. The quality and reliability of models were confirmed by QMEAN and RAMPAGE software.

By examining all the predictions core epitopes with and without signal peptide, we found out that there is no difference between these two different strategies of analysis (Pene et al. 2009; Targett-Adams et al. 2008; Ma et al. 2007; Okamoto et al. 2008; Oehler et al. 2012).

Based on previous studies core protein has a $\mathrm{C}$ terminal signal peptide (170-191) and because the focus of our study was on domain 1 , it was expected that the deletion of this region could not affect the epitope perdition results.

Digestion analysis to predict possible proteases was shown that each epitope can be digested by at least 5 
selected proteases which can have a significant effect on the reduction of the half-life of epitopes.

\section{Conclusion}

Finally our investigations in this research provided comprehensive data about frequent mutations in domain1, and as a first report can be useful for future study about significant mutations and their role in therapeutic pathway and response to antiviral therapy for Iranian patients. Also, identification of domain 1 properties provides practical information for domain 1 cloning and more researches.

Acknowledgements The authors would like to acknowledge Shiraz University of Medical Sciences for financial support (Grant Number: 95-01-59-13086) and Jean Krugman, retired professor of General Studies, DeVry University, Decatur, Georgia, USA for help in revising the English of the manuscript.

Funding This study was funded by Shiraz University of Medical Sciences (Grant Number: 95-01-59-13086).

\section{Compliance with Ethical Standards}

Conflict of interest Authors declare there is no conflict of interest.

Research Involving Human and/or Animal Participants This article does not contain any studies with human participants or animals performed by any of the authors.

\section{References}

Aghasadeghi M, Sadat S, Budkowska A, Khabiri A, Amini S, Bahramali $\mathrm{G}$ et al (2006) Evaluation of a native preparation of $\mathrm{HCV}$ core protein (2-122) for potential applications in immunization, diagnosis and $\mathrm{mAb}$ production. Iran J Public Health 35(1):1-10

Ajorloo M, Bamdad T, Hashempour T, Alborzi AM, Mozhgani SHR, Asadi R et al (2015) Detection of specific antibodies to HCV$\mathrm{ARF} / \mathrm{CORE}+1$ protein in cirrhotic and non-cirrhotic patients with hepatitis $\mathrm{C}$ : a possible association with progressive fibrosis. Arch Iran Med AIM 18(5):304-307

Akuta N, Suzuki F, Kawamura Y, Yatsuji H, Sezaki H, Suzuki Y et al (2007) Amino acid substitutions in the hepatitis $C$ virus core region are the important predictor of hepatocarcinogenesis. Hepatology 46(5):1357-1364

Akuta N, Suzuki F, Hirakawa M, Kawamura Y, Yatsuji H, Sezaki H et al (2010) Amino acid substitution in hepatitis $\mathrm{C}$ virus core region and genetic variation near the interleukin $28 \mathrm{~B}$ gene predict viral response to telaprevir with peginterferon and ribavirin. Hepatology 52(2):421-429

Akuta N, Suzuki F, Hirakawa M, Kawamura Y, Sezaki H, Suzuki Y et al (2011) Amino acid substitutions in hepatitis $\mathrm{C}$ virus core region predict hepatocarcinogenesis following eradication of $\mathrm{HCV}$ RNA by antiviral therapy. J Med Virol 83(6):1016-1022

Alborzi AM, Bamdad T, Davoodian P, Hashempoor T, Nejatizadeh AA, Moayedi J (2015) Insights into the role of HCV Plus-/Minus strand RNA, IFN- $\gamma$ and IL-29 in relapse outcome in patients infected with HCV. Asian Pac J Allergy Immunol 33(3):173-181
Alborzi A, Hashempour T, Moayedi J, Musavi Z, Pouladfar G, Merat S (2017) Role of serum level and genetic variation of IL-28B in interferon responsiveness and advanced liver disease in chronic hepatitis C patients. Med Microbiol Immunol 206(2):165-174

Alestig E, Arnholm B, Eilard A, Lagging M, Nilsson S, Norkrans $\mathrm{G}$ et al (2011) Core mutations, IL28B polymorphisms and response to peginterferon/ribavirin treatment in Swedish patients with hepatitis $\mathrm{C}$ virus genotype 1 infection. BMC Infect Dis 11(1):124

Arashkia A, Rouhvand F, Memarnejadian A, Alizadeh S, Motevalli F, Ebrahimi M (2011) Immunoinformatics modeling, construction of DNA plasmids Carrying CTL epitopes of hepatitis C virus and their preliminary immunological analysis. Iran J Med Microbiol 4(4):30-40

Atapour A, Mokarram P, MostafaviPour Z, Hosseini SY, Ghasemi Y, Mohammadi S et al (2018) Designing a fusion protein vaccine against HCV: an in silico approach. Int J Peptide Res Ther. https ://doi.org/10.1007/s10989-018-9735-4

Benkert P, Tosatto SC, Schomburg D (2008) QMEAN: A comprehensive scoring function for model quality assessment. Proteins 71(1):261-277

Bhasin M, Raghava G (2004) Prediction of CTL epitopes using QM, SVM and ANN techniques. Vaccine 22(23-24):3195-3204

Blom N, Gammeltoft S, Brunak S (1999) Sequence and structurebased prediction of eukaryotic protein phosphorylation sites 1 . J Mol Biol 294(5):1351-1362

Blom N, Sicheritz-Pontén T, Gupta R, Gammeltoft S, Brunak S (2004) Prediction of post-translational glycosylation and phosphorylation of proteins from the amino acid sequence. Proteomics 4(6): 1633-1649

Cashman SB, Marsden BD, Dustin LB (2014) The humoral immune response to $\mathrm{HCV}$ : understanding is key to vaccine development. Front Immunol 5:550

Caval V, Piver E, Ivanyi-Nagy R, Darlix J-L, Pagès J-C (2011) Packaging of HCV-RNA into lentiviral vector. Biochem Biophys Res Commun 414(4):808-813

Chauhan JS, Rao A, Raghava GP (2013) In silico platform for prediction of N-, O-and C-glycosites in eukaryotic protein sequences. PLoS ONE 8(6):e67008

Chen C-C, Hwang J-K, Yang J-M (2006) 2: Protein structure prediction server. Nucleic Acids Res 34(suppl_2):W152-W157

Chou P, Fasman GD (2009) Amino acid sequence. Adv Enzymol Relat Areas Mol Biol 47:45

Cristofari G, Ivanyi-Nagy R, Gabus C, Boulant S, Lavergne JP, Penin F et al (2004) The hepatitis C virus Core protein is a potent nucleic acid chaperone that directs dimerization of the viral (+) strand RNA in vitro. Nucleic Acids Res 32(8):2623-2631

Dehghani B, Rasooli I, Gargari SLM, Nadooshan MRJ, Owlia P, Nazarian S (2013) Immunogenicity of Salmonella enterica serovar Enteritidis virulence protein, InvH, and cross-reactivity of its antisera with Salmonella strains. Microbiol Res 168(2):84-90

Dehghani B, Rasooli I, Jalali-Nadoushan M, Owlia P, Rasooli Z (2014) Immunoprotectivity of Salmonella enterica serovar Enteritidis virulence protein, InvH, against Salmonella typhi. Iran J Basic Med Sci 17(8):560

Dehghani B, Ghasabi F, Hashempoor T, Joulaei H, Hasanshahi Z, Halaji $M$ et al (2017) Functional and structural characterization of Ebola virus glycoprotein (1976-2015) - An in silico study. Int J Biomath 10(08):1750108

Dehghani B, Hashempour T, Zahra H (2019) Using immunoinformatics and structural approaches to design a novel HHV8 vaccine. Int J Peptide Res Ther; In Press

Doytchinova IA, Flower DR (2007) VaxiJen: a server for prediction of protective antigens, tumour antigens and subunit vaccines. BMC Bioinform 8(1):4 
Emini EA, Hughes JV, Perlow D, Boger J (1985) Induction of hepatitis A virus-neutralizing antibody by a virus-specific synthetic peptide. J Virol 55(3):836-839

Farag RE, Arafa MM, El-Etreby S, Saudy NS, Eldeek BS, El-Alfy HA et al (2013) Human leukocyte antigen class I alleles can predict response to pegylated interferon/ribavirin therapy in chronic hepatitis C Egyptian patients. Arch Iran Med 16(2):68

Ferroni P, Mascolo G, Zaninetti M, Colzani D, Pregliasco F, Pirisi M et al (1993) Identification of four epitopes in hepatitis $C$ virus core protein. J Clin Microbiol 31(6):1586-1591

Fishman SL, Factor SH, Balestrieri C, Fan X, DiBisceglie AM, Desai $\mathrm{SM}$ et al (2009) Mutations in the hepatitis $\mathrm{C}$ virus core gene are associated with advanced liver disease and hepatocellular carcinoma. Clin Cancer Res 15(9):3205-3213

Furui Y, Hoshi Y, Murata K, Ito K, Suzuki K, Uchida S et al (2011) Prevalence of amino acid mutation in hepatitis $C$ virus core region among Japanese volunteer blood donors. J Med Virol 83(11):1924-1929

Gasteiger E, Hoogland C, Gattiker A, Wilkins MR, Appel RD, Bairoch A (2005) Protein identification and analysis tools on the ExPASy server. In: Walker JM (ed) The proteomics protocols handbook. Springer, New York, pp. 571-607

Gededzha MP, Mphahlele MJ, Selabe SG (2014) Prediction of T-cell epitopes of hepatitis C virus genotype 5a. Virol J 11(1):187

Geourjon C, Deleage G (1995) SOPMA: significant improvements in protein secondary structure prediction by consensus prediction from multiple alignments. Bioinformatics 11(6):681-684

Gremion C, Cerny A (2005) Hepatitis C virus and the immune system: a concise review. Rev Med Virol 15(4):235-268

Gupta R, Brunak S (2001) Prediction of glycosylation across the human proteome and the correlation to protein function. In: 2002 Biocomputing, World Scientific. pp. 310-322

Harase I, Moriyama T, Kaneko T, Kita H, Nomura M, Suzuki G et al (1995) Immune response to hepatitis $C$ virus core protein in mice. Immunol Cell Biol 73(4):346

Hashempoor T, Bamdad T, Merat S, Janzamin E, Nemati L, Jabbari $\mathrm{H}$ et al (2010) Expansion of CD4+ CD25+ FoxP3+ regulatory $\mathrm{T}$ cells in chronic hepatitis $\mathrm{C}$ virus infection. Iran $\mathrm{J}$ Immunol 7(3): 177-185

Hashempoor T, Alborzi AM, Moayedi J, Ajorloo M, Bamdad T, Sharifi AH et al (2018) A decline in anti-core +1 antibody titer occurs in successful treatment of patients infected with hepatitis C virus. Jundishapur J Microbiol 11(2):e58294

Hashempour T, Bamdad T, Bergamini A, Lavergne JP, HajSheykholeslami A, Brakier-Gingras L et al (2015) F protein increases CD4+ CD25+ T cell population in patients with chronic hepatitis C. Pathog Dis 73(4):ftv022

Horie T, Shimizu I, Horie C, Yogita S, Tashiro S, Ito S (1999) Mutations of the core gene sequence of hepatitis $\mathrm{C}$ virus isolated from liver tissues with hepatocellular carcinoma. Hepatol Res 13(3):240-251

Iakoucheva LM, Radivojac P, Brown CJ, O'Connor TR, Sikes JG, Obradovic Z et al (2004) The importance of intrinsic disorder for protein phosphorylation. Nucleic Acids Res 32(3): 1037-1049

Idrees S, Ashfaq UA (2013) HCV infection and NS-3 serine protease inhibitors. Virol Mycol 2(112):2160-2161

Ivanyi-Nagy R, Kanevsky I, Gabus C, Lavergne J-P, Ficheux D, Penin F et al (2006) Analysis of hepatitis C virus RNA dimerization and core-RNA interactions. Nucleic Acids Res 34(9):2618-2633

Jazayeri SM, Carman WF (2005) Virus escape CTL or B cell epitopes? Hapat Mon 5(4):133-136

Karplus P, Schulz G (1985) Prediction of chain flexibility in proteins. Naturwissenschaften 72(4):212-213

Kelley LA, Sternberg MJ (2009) Protein structure prediction on the Web: a case study using the Phyre server. Nat Protoc 4(3):363
Khorrami S, Mohammadpour H, Shahzamani K, Zarif MN, Sharifi AH, Merat $\mathrm{S}$ et al (2015) The relationship between HLA-G and viral loads in non-responder HCV-infected patients after combined therapy with IFN- $\alpha 2 \alpha$ and ribavirin. Hum Immunol 76(2-3):181-186

Larsen JEP, Lund O, Nielsen M (2006) Improved method for predicting linear B-cell epitopes. Immunome Re 2(1):2

Lauer GM, Walker BD (2001) Hepatitis C virus infection. N Engl J Med 345(1):41-52

Lavanchy D (2011) Evolving epidemiology of hepatitis C virus. Clin Microbiol Infect 17(2):107-115

Lechmann M, Ihlenfeldt HG, Braunschweiger I, Giers G, Jung G, Matz B et al (1996) T-and B-cell responses to different hepatitis $C$ virus antigens in patients with chronic hepatitis $C$ infection and in healthy anti-hepatitis $\mathrm{C}$ virus-positive blood donors without viremi. Hepatology 24(4):790-795

Lu W, Ou J-h (2002) Phosphorylation of hepatitis C virus core protein by protein kinase A and protein kinase C. Virology 300(1):20-30

Ma H-C, Ku Y-Y, Hsieh Y-C, Lo S-Y (2007) Characterization of the cleavage of signal peptide at the $\mathrm{C}$-terminus of hepatitis $\mathrm{C}$ virus core protein by signal peptide peptidase. J Biomed Sci 14(1):31-41

Martro E, Valero A, Jordana-Lluch E, Saludes V, Planas R, GonzálezCandelas F et al (2011) Hepatitis C virus sequences from different patients confirm the existence and transmissibility of subtype $2 \mathrm{q}$, a rare subtype circulating in the metropolitan area of Barcelona, Spain. J Med Virol 83(5):820-826

Moattari A, Dehghani B, Khodadad N, Tavakoli F (2015) In silico functional and structural characterization of H1N1 influenza A viruses hemagglutinin, 2010-2013, Shiraz, Iran. Acta Biotheor 63(2): 183-202

Moayedi J, Hashempour T, Musavi Z, Hallaji M, Ghasabi F, HajSheykholeslami A et al (2018) Comparison of IL-28B favorable genotype frequency between healthy and patients infected with HCV. Sci J Ilam Univ Med Sci 26(2):28-36

Netski DM, Mosbruger T, Depla E, Maertens G, Ray SC, Hamilton RG et al (2005) Humoral immune response in acute hepatitis $C$ virus infection. Clin Infect Dis 41(5):667-675

Neumann-Haefelin C, Blum HE, Chisari F, Thimme R (2005) T cell response in hepatitis $C$ virus infection. J Clin Virol 32(2):75-85

Nezafat N, Dorosti H, Zarei M, Ghasemi Y (2018) Exploring dengue proteome to design an effective epitope-based vaccine against dengue virus AU-Sabetian, Soudabeh. J Biomol Struct Dyn. https:// doi.org/10.1080/07391102.2018.1491890

Oehler V, Filipe A, Montserret R, Da Costa D, Brown G, Penin F et al (2012) Structural analysis of hepatitis $C$ virus core-E1 signal peptide and requirements for cleavage of the genotype 3a signal sequence by signal peptide peptidase. J Virol 86(15):7818-7828

Ogata S, Nagano-Fujii M, Ku Y, Yoon S, Hotta H (2002) Comparative sequence analysis of the core protein and its frameshift product, the $\mathrm{F}$ protein, of hepatitis $\mathrm{C}$ virus subtype $1 \mathrm{~b}$ strains obtained from patients with and without hepatocellular carcinoma. J Clin Microbiol 40(10):3625-3630

Okamoto K, Mori Y, Komoda Y, Okamoto T, Okochi M, Takeda M et al (2008) Intramembrane processing by signal peptide peptidase regulates the membrane localization of hepatitis $C$ virus core protein and viral propagation. J Virol 82(17):8349-8361

Parker J, Guo D, Hodges R (1986) New hydrophilicity scale derived from high-performance liquid chromatography peptide retention data: correlation of predicted surface residues with antigenicity and X-ray-derived accessible sites. Biochemistry 25(19):5425-5432

Pavio N, Lai MM (2003) The hepatitis C virus persistence: how to evade the immune system? J Biosci 28(3):287-304

Pene V, Hernandez C, Vauloup-Fellous C, Garaud-Aunis J, Rosenberg A (2009) Sequential processing of hepatitis $C$ virus core protein 
by host cell signal peptidase and signal peptide peptidase: a reassessment. J Viral Hepat 16(10):705-715

Pirisi M, Fabris C, Toniutto P, Vitulli D, Soardo G, Falleti E et al (1995) Reactivity to B cell epitopes within hepatitis C virus core protein and hepatocellular carcinoma. Cancer Res 55(1):111-114

Polyak SJ, Klein KC, Shoji I, Miyamura T, Lingappa JR (2006) Assemble and interact: pleiotropic functions of the HCV core protein. Hepatitis C viruses: genomes and molecular biology. Horizon Bioscience, Norwich, pp. 89-119

Pourhassan A. Hepatitis C (2014) The first report in Azeri patients. Pak J Biol Sci 17(6):872-875

Roy A, Kucukural A, Zhang Y (2010) I-TASSER: a unified platform for automated protein structure and function prediction. Nat Protoc $5(4): 725$

Sabet LP, Taheri T, Memarnejadian A, Azad TM, Asgari F, Rahimnia $\mathrm{R}$ et al (2014) Immunogenicity of multi-epitope DNA and peptide vaccine candidates based on core, E2, NS3 and NS5B HCV epitopes in BALB/c mice. Hepat Mon 14(10):e22215

Saeedi A, Naderi M, Tabarraie A, Kelishdi M, Ghaemi A (2014) Enhanced immune responses of a hepatitis $\mathrm{C}$ virus core DNA vaccine by co-inoculating interleukin-12 expressing vector in mice. Vaccine Res 1(2):29-33

Saha S, Raghava GP (2004) BcePr(ed): prediction of continuous B-cell epitopes in antigenic sequences using physico-chemical properties. In: Saha S, Raghava GP (eds) International conference on artificial immune systems. Springer

Saha S, Raghava G (2006a) Prediction of continuous B-cell epitopes in an antigen using recurrent neural network. Proteins 65(1):40-48

Saha S, Raghava G (2006b) AlgPred: prediction of allergenic proteins and mapping of IgE epitopes. Nucleic Acids Res 34(suppl_2):W202-W209

Samimi-Rad K, Sadeghi F, Amirzargar A, Eshraghian MR, Alavian SM, Rahimnia R (2015) Association of HLA class II alleles with hepatitis $\mathrm{C}$ virus clearance and persistence in thalassemia patients from Iran. J Med Virol 87(9):1565-1572

Sarvari J, Mojtahedi Z, Kuramitsu Y, Fattahi MR, Ghaderi A, Nakamura $\mathrm{K}$ et al (2014) Comparative proteomics of sera from HCC patients with different origins. Hepat Mon 14(1):e13103
Sefidi FJ, Keyvani H, Monavari SH, Alavian SM, Fakhim S, BokharaeiSalim F (2013) Distribution of hepatitis C virus genotypes in Iranian chronic infected patients. Hepat Mon 13(1):e7991

Shih C-M, Chen C-M, Chen S-Y, Lee Y (1995) Modulation of the trans-suppression activity of hepatitis $\mathrm{C}$ virus core protein by phosphorylation. J Virol 69(2):1160-1171

Singh H, Raghava G (2001) ProPred: prediction of HLA-DR binding sites. Bioinformatics 17(12):1236-1237

Singh H, Raghava G (2003) ProPred1: prediction of promiscuous MHC Class-I binding sites. Bioinformatics 19(8):1009-1014

Steinmann E, Brohm C, Kallis S, Bartenschlager R, Pietschmann T (2008) Efficient trans-encapsidation of hepatitis C virus RNAs into infectious virus-like particles. J Virol 82(14):7034-7046

Strosberg AD, Kota S, Takahashi V, Snyder JK, Mousseau G (2010) Core as a novel viral target for hepatitis $\mathrm{C}$ drugs. Viruses 2(8):1734-1751

Takahashi K, Iwata K, Matsumoto M, Matsumoto H, Nakao K, Hatahara T et al (2001) Hepatitis C virus (HCV) genotype 1b sequences from fifteen patients with hepatocellular carcinoma: the 'progression score'revisited. Hepatol Res 20(2):161-171

Targett-Adams P, Hope G, Boulant S, McLauchlan J (2008) Maturation of hepatitis $\mathrm{C}$ virus core protein by signal peptide peptidase is required for virus production. J Biol Chem 283(24):16850-16859

Tokita H, Kaufmann GR, Matsubayashi M, Okuda I, Tanaka T, Harada $\mathrm{H}$ et al (2000) Hepatitis $\mathrm{C}$ virus core mutations reduce the sensitivity of a fluorescence enzyme immunoassay. J Clin Microbiol 38(9):3450-3452

Ward S, Lauer G, Isba R, Walker B, Klenerman P (2002) Cellular immune responses against hepatitis $\mathrm{C}$ virus: the evidence base 2002. Clin Exp Immunol 128(2):195-203

Yassin K (2001) Unraveling the mystery of liver diseases in Egypt. Jacobs Verlag, Lage

Publisher's Note Springer Nature remains neutral with regard to jurisdictional claims in published maps and institutional affiliations. 